\title{
MODEL OF INTEGRATION OF FORMAL AND INFORMAL EDUCATION FOR STUDENT-ATHLETES
}

\section{Almaz Galimov, Liubov Botova, Andrey Nazarenko, Marat Galyautdinov}

Volga Region State Academy of Physical Culture, Sport and Tourism, Kazan, Russia

\begin{abstract}
A majority of the students at physical education universities are actual athletes who have "double career". They combine getting professional education with professional sport activities. In this regard, sport activities of students form an important part of their future career, because it is the informal way of getting professional knowledge and skills. However, today there are no officially recognized organizational and pedagogical approaches to the formalization and assessment of informal education outcomes, which student-athletes demonstrate during their sport activities. Consequently, there are very few practices of making individual university programs for student-athletes based on their informal education outcomes. The study purpose was to develop and approbate a model of substantial integration of study process and sport training at the sports university as a method of combination of formal and informal education types for student-athletes. The study included a comparative analysis of educational and professional standards, elaboration of measures for substantial integration of sport and educational process, and study of athletes' academic performance. In addition, we used methods of modeling, interviewing, expert assessment and mathematical statistics in our study. The study revealed the coherence of athletes'knowledge, skills and activities and the competencies they acquire at the sports university. We demonstrated that elite athletes gain knowledge, skills and attitudes envisaged in the educational program in the framework of their sport activities. We have designed the model of individual university program for elite athletes, which corresponds to the techniques of integration of formal and informal education types.
\end{abstract}

Key words: higher education, sport training, integration, quality of education, informal education.

\section{INTRODUCTION}

The common problem of higher physical education is the organization of education for elite student-athletes. This problem occurs because they are required to spend much time at sport training camps (Abelkalns, 2012, 2013, Forster, 2010). For this reason, elite studentathletes do not often demonstrate high academic achievements. Meanwhile a majority of the student-athletes obtains high credits during final assessment and demonstrates a high total level of professional competencies. For example, the average academic performance of student-athletes in Volga Region State Academy of Physical Culture and Sport was 26,3 per cent lower than the results of final exams. It means that elite student-athletes demonstrate higher level of professional knowledge and skills acquired upon completion of academic courses in comparison with other students.

We suppose that elite athletes acquire a certain amount of knowledge, skills and experience closely connected with the requirements of the training program for coaches in the framework of their sport activities. Such training called informal education occurs in day-to-day life or in 
professional activities. According to Christian Dumitrescu (Dumitrescu, 1999), the main difference between formal and informal education is that the first one is non-voluntary and passive while the latter is the output of individual voluntary activity and is primarily active.

Therefore, sport activities enhance the development of professional and coach competencies of athletes in the framework of informal education. However, this creates an organizational and pedagogical challenge how to assess the development of professional competencies of student-athletes who study coach-training programs. It is a very topical problem for sports universities at least in the Russian Federation.

Unfortunately, today there are no information resources about the issues of comprehensive integration of educational activity and sport training of students. Information we get from international literature (The Guardian, 2017, Victoria University, 2017, Gustin, 2017, University Sports of Oulu, 2017, The University Adelaide, 2017, European Parliament, 2017) tend to reveal organizational aspects of the problem of combination of sport and academic activity of elite athletes ${ }^{1}$. There are descriptions of the support programs that help athletes to find a balance between the study process and individual requirements for educational activity, which are as follows:

- Implementation of alternative examination forms

- Implementation of individual terms of study completion

- Introduction of a flexible timetable

- Cross-institutional study assistance.

Russian researchers examine the issues of organizational, pedagogical and technological support of the educational process for studentathletes, through the application of distant learn- ing technologies (Galimov, 2016, Kotlyarova 2015), cluster interaction of educational and sport bodies (Latypov, 2013), individualization of educational process (Afanasyeva, 2016), etc.

Nowadays there are some research papers demonstrating the necessity of alignment of qualification requirements of professional standards and professional competencies developed by learners during the study process (Galimov, 2017, Fedorov, 2017).

\section{METHODOLOGY}

For achieving the goal of the current research, we carried out a comparative analysis of the higher education standard for coachtraining programs and the professional "Athlete" standard. We analyzed academic performance of student-athletes in Volga Region State Academy of Physical Culture and Sport. We used such methods as interviewing, questionnaires, and expert assessment to examine if student-athletes were satisfied with the educational environment.

In the experimental part of our research we carried out quality assessment of some professional competencies acquired by studentathletes in the framework of "Technologies of sport training in favored sports", "Human physiology", "Sport physiology" and "Refinement of professional and sport achievements" courses. The experiment brought together 18 student-athletes doing centralized sport training either in federal training centers or in professional sport clubs (an experimental group), and 20 students with no prior centralized training experience (a control group).

The experiment included the following organizational and pedagogical activities:

1. Creating lists of expected program learning outcomes corresponding to professional competencies;

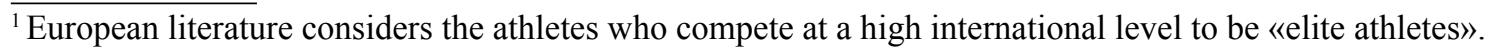


2. Creating lists of athlete's knowledge, skills and actions for every course, which correspond to the expected outcomes;

3 . Identification of the fields of content integration of academic course and sport activity, through comparison of the range of expected academic outcomes and athletes' relevant knowledge, skills and actions;

4. Student-athletes involved in the experiment did not make current academic tasks on the development of competencies which had the similar content with the professional "Athlete" standard;

5. All students passed through the interim attestation according to the unified pool of rating tools.

Figure 1 presents a graphical image of the algorithm of content integration of educational process and sport activity for a certain studentathlete in the framework of a certain academic course.

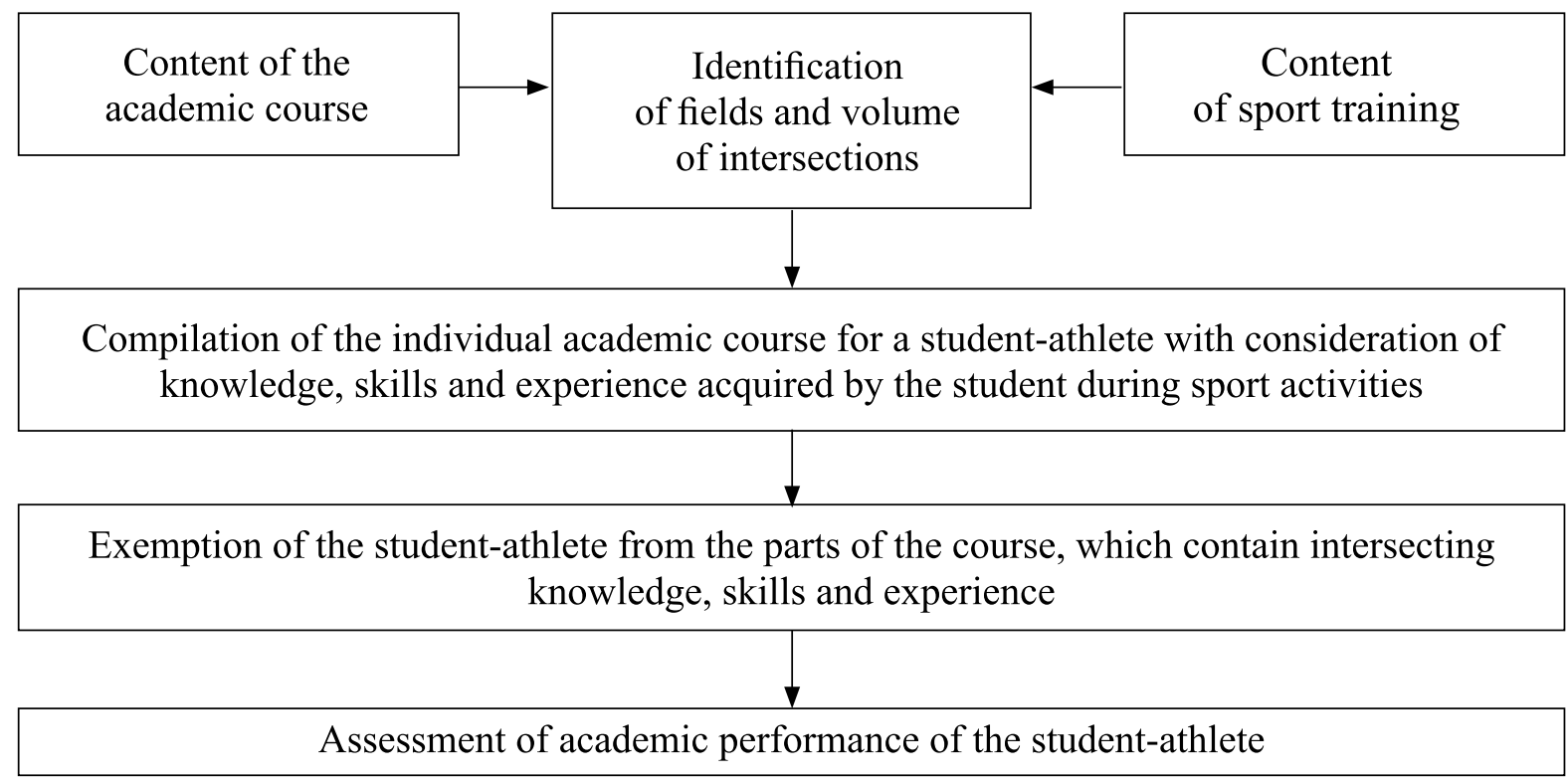

Figure 1. Algorithm of the content integration of educational process and sport activity in the framework of the academic course

Table 1 presents an example of determination and formalization of the volume of intersections (integration) of study materials and sport activity in the framework of the "Technologies of sport training in favored sports" course.

Table 1. The example of integration of content of educational process and sport training in the framework of the "Technologies of sport training in favored sports" course.

\begin{tabular}{lcccc}
\hline \multicolumn{1}{c}{ Criteria } & \multicolumn{3}{c}{ Competencies } \\
\cline { 2 - 5 } & OK-7 & PK-10 & PK-13 & PK-29 \\
\hline $\begin{array}{l}\text { The quantity of planned learning outcomes } \\
\text { The quantity of planned learning outcomes inter- }\end{array}$ & 24 & 9 & 19 & 9 \\
$\begin{array}{l}\text { secting with knowledge, skills and experience of an } \\
\text { athlete }\end{array}$ & 14 & 5 & 15 & 4 \\
$\begin{array}{l}\text { The volume of content integration of the academic } \\
\text { course and sport training (\%) } \\
\begin{array}{l}\text { Contribution of sport activities to the final credits } \\
\text { for the academic course (10-point scale) }\end{array}\end{array}$ & 58 & 56 & 79 & 44 \\
\hline
\end{tabular}


It is evident that the examined academic course focuses on the development of the following competencies:

1. capacity for self-organization and selfeducation (OK-7);

2. ability to implement the system of selection and sport orienteering in favored sports with the use of modern techniques for determination of anthropometric, physical and psychic features of students (PK-10);

3. ability to use technologies of the management of human condition, which are relevant for the favored sports, including pedagogical control and correction (PK13);

4. ability to implement methods of processing research results with the use of methods of mathematical statistics and information technologies, to formulate and present conclusions.

We identified the volume of content integration of the academic course and sport training for a student.

We carried out a pedagogical experiment. We divided the materials of the "Technologies of sport training in favored sports" course into two parts. The first part contained materials and tasks studied by students in the framework of formal education (in classes or by distance learning). The second part consisted of academic materials available for students within their sport activities. The experimental group of elite student-athletes studied academic materials from the first part only during the semester, but they had to pass the final exams of both parts at the end of the semester.

We used math-statistical methods to process the results. We applied the Student criterion for independent selection (a double selective t-test) in order to identify statistically significant difference between the groups surveyed. The whole range of data was explored for the normality of a distribution with the use of the Kolmogorov-Smirnov/Lilliefors criterion, and it complies with the law of a normal distribution.

We carried out the experiment focused on exploring the comfort of educational environment among selected 20 student-athletes at the beginning and at the end of the first academic semester 2017-2018. In our research, we used the "Assessment of Psychic Activation, Interest, Emotional Tonus, Strain and Comfort" techniques elaborated by N.A. Kurganskii (1990), and our own questionnaire.

Our questionnaire aimed at the investigation of student-athletes' satisfaction with the following major aspects: the opportunity for studying and combining educational, cognitive, social, communicative, training and competitive activities; the opportunity for regulating courses timetable; study process, conditions and outcomes; prompt feedback from the participants of educational process; correspondence between somatic, physical needs and spatial conditions of educational environment.

\section{RESULTS}

A comparative analysis of the above-mentioned standards and the results of interviews revealed that the student-athletes involved in centralized training acquired a significant number of competencies during their training and competitive activities. For example, members of the Russian national team acquire general cultural competencies while interacting with a great number of people: teammates, coaches, administrative staff, and judges. When athletes go to international competitions they have to speak various languages, negotiate with competition managers, meet day-to-day challenges, and all these activities contribute to the development of competencies characterizing numerous interpersonal relations and commu- 
nications.

Athletes get an insight into the fundamentals of economic knowledge in various fields of life when they help their coaches to calculate expenses for competitions. Athletes get legal knowledge in various fields of life in the framework of their labor activity and sector-specific actions aimed at protection of their rights and awareness of their responsibilities when passing through the doping control procedure.

The ability to develop social and personal qualities of students: persistence, self-organization, hardworking nature, responsibility, patriotic thinking, communicativeness, and tolerance, can be acquired in the process of assisting their coaches during training period, and if athletes are team leaders. Furthermore, athletes often deal with the procedures of control and assessment of both physical abilities and technical skills of teammates, younger generation, and their own performance (based on video records). They are able to use favored sport tools for promotion of healthy lifestyle attitudes. Similarly, athletes are obliged to have appropriate skills and abilities in the field of life safety measures, sanitary and hygienic norms, prevention of injuries and provision of emergency assistance.

Due to his great experience, a professional athlete also has an overview of competition organizing and refereeing, can use information and communication technologies.

Talking about professional competencies of pedagogical activity, there is a number of similarities with the professional standard, e.g. an athlete is supposed to be aware of theoretical fundamentals of physical education and sports (at all qualification levels). Due to their professional activity, athletes have to be aware of sport training standards and their indicators in various training periods. Considering knowledge and personal experience in determination of trends of sport development, we can speak about possibility of qualitative selection of students in various training periods. According to the professional standard, athletes have to be able to control their own physical and emotional health, to be aware of the structure of control exercises aimed at the assessment of general and specific physical fitness.

There is no doubt that athletes acquire the ability of refinement of individual sport performance during training sessions. Elite athletes who compete at a high international level can reveal relevant issues in the field of physical education and sports as well.

Therefore, our study revealed a significant content intersection of requirements for skills and abilities of athletes, and professional competencies of perspective coaches. It became evident during interviews with student-athletes. They noted that when choosing an educational institution, they clearly understood that they would have to combine sport career and education process. They understood that their sports career could simplify the studying process. That is why they preferred coaching profession.

Of course, studying at the university is a complicated process, particularly for the students who spend much time in training camps. Nevertheless, student-athletes think that they can master the educational program for coaches easier than ordinary students.

From Table 1 we can see that an elite student-athlete is able to learn up to $62 \%$ of the "Technologies of sport training in favored sports" course materials in the framework of his sport activities. Of course, a student-athlete should get a leave of absence from studying integrated academic materials during the academic semester, and this is the core point of the individual approach to the planning of the academic studies.

The comparative analysis of the exam results revealed no significant differences between experimental and control groups (Table 2). 
Table 2. Comparison of the academic performance of student-athletes participating in the experiment

\begin{tabular}{lcccc}
\hline \multicolumn{1}{c}{ Groups } & Frequency & $\begin{array}{c}\text { Current } \\
\text { performance }\end{array}$ & $\begin{array}{c}\text { Examinee } \\
\text { answers }\end{array}$ & Final points \\
\hline Control $(\mathrm{n}=20)$ & $8,52 \pm 1,91^{*}$ & $38,08 \pm 8,34^{*}$ & $46,13 \pm 4,08$ & $83,21 \pm 10,45^{*}$ \\
Experimental $(\mathrm{n}=20)$ & $3 \pm 1,91$ & $11,21 \pm 4,2$ & $42,1 \pm 4,41$ & $87 \pm 6,34$ \\
$\mathrm{P}$ & $\leq 0,01$ & $\leq 0,01$ & $\geq 0,05$ & $\geq 0,05$ \\
\hline
\end{tabular}

Note - * differences between control and experimental groups $(P \leq 0,05)$

Having analyzed the data in Table 2, we can affirm that there are statistically significant differences existing in indicators of academic frequency, and that occurs when a great number of students leave for centralized training and competitions. It is notable that without integrative approach student-athletes obtain low number of credits when making typical tasks of relevant program modules because of their engagement in professional sphere, nevertheless they successfully cope with the current attestation (tests). We can see in Table 2 that the student-athletes cope with the demands if they use the developed approach - additional test questions, and as a result there is no statistical significance between final credits $87 \pm 6,34$ and $83,21 \pm 10,45$ in experimental and control groups respectively.

We carried out the same multi-step activities for other academic courses in the coachtraining curriculum. The results from the experiment demonstrate that the offered model of the organization of educational process allows integration of formal and informal education of student-athletes in the framework of their educational and sport activities.

We explored such student conditions as psychic activation, interest, emotional tonus, strain and comfort with the use of these techniques.

We assessed the comfort levels of educational environment at the university according to certain indicators characterizing psychological, intellectual and physical comfort parameters (Table 3).

Table 3. Outcomes of the analysis of the comfort level of educational environment

\begin{tabular}{cccccc}
\hline $\begin{array}{c}\text { Satisfaction } \\
\text { levels }\end{array}$ & $\begin{array}{c}\text { Unit of } \\
\text { measurement }\end{array}$ & \multicolumn{2}{c}{ Survey results (1 ${ }^{\text {st }}$ phase) } & \multicolumn{2}{c}{ Survey results $\left(2^{\text {nd }}\right.$ phase) } \\
\hline Low & individuals & $\begin{array}{c}\text { Control } \\
\text { group }\end{array}$ & $\begin{array}{c}\text { Experimental } \\
\text { group }\end{array}$ & $\begin{array}{c}\text { Control } \\
\text { group }\end{array}$ & $\begin{array}{c}\text { Experimental } \\
\text { group }\end{array}$ \\
\hline \multirow{4}{*}{ Medium } & $\%$ & 0 & 3 & 0 & 1 \\
& individuals & 9 & 15 & 0 & 5 \\
High & $\%$ & 45 & 13 & 10 & 14 \\
& individuals & 11 & 65 & 50 & 70 \\
& $\%$ & 55 & 4 & 10 & 5 \\
\hline
\end{tabular}

Here we can see that at the first phase, satisfied with the organization of educational three student-athletes considered the comfort of educational environment to be on the low level, 13 student-athletes considered it to be on the medium level. At the second phase, there were only one student-athlete left disprocess. We registered the increasing number of student-athletes who had turned to assess the comfort of educational process on medium and high levels.

Furthermore, we carried out a comparative 
analysis of the comfort levels of educational environment for control and experimental groups at the $1^{\text {st }}$ and $2^{\text {nd }}$ phases with the data from the Table 5. Satisfaction parameters in control and experimental groups at the early experimental period ( $1^{\text {st }}$ phase) were significantly different. The control group demonstrated much higher satisfaction. At the end of the experiment $\left(2^{\text {nd }}\right.$ phase) there was no statistically evident difference between the groups.

\section{CONCLUSION}

The research revealed that conceptual fundamental for integration of the educational process and sport training depends on the competence approach to the organization of higher education, which considers knowledge, skills and activities in the framework of the professional "Athlete" standard to be the expected program learning outcomes. In this regard, integration of study process and sport activities of students should be formalized into characteristic features of educational program considering specifics and content of sport activities.

We have developed and experimentally tested the techniques for the quality assessment of acquiring competencies based on the identification of content compliance with the professional "Athlete" standard requirements. It has been demonstrated that implementation of the developed techniques for quality assessment of acquiring competencies when studying academic courses increases satisfaction of student-athletes with the conditions of organization of educational process at the sports university. The findings of this study in the form of practical recommendations for the integration of educational process and sport training are applicable for coach-training programs.

\section{REFERENCES}

Abelkalns, I. (2012). Possibilities of creation of environment for the dual career of elite athletes // Physical culture and student sport: problems of implementing a development strategy. Kazan: State University, pp.194-199.

Abelkalns, I., Geske, A. (2013). High performance athletes' dual career possibilities in Latvian higher educational institutions // LASE Journal of sport science. Vol. 4. Nr.2, pp. 47-60.

Afanasieva, V.M.,Zotova, F.R.(2016). Model of the integration of educational and training process of elite athletes // Problems and prospects of physical education, sport training and adaptive physical culture. Proceedings of the All-Russian Conference on Science and Practice with international participation. FGBOU VO "Volga Region State Academy of Physical Culture, Sports and Tourism”. pp. 117-120.

Do athletes make better students? The Guardian. Electronic resource https://www. theguardian.com/education/2014/aug/04/ sport-at-university-do-athletes-make-betterstudents. (Access mode- 05.05.2017).

Elite student athletes. Victoria University. Electronic resource https://www.vu.edu. au/current-students/campus-life/sport-fitness/elite-student-athletes. (Access mode 19.04.2017).

Federal State Educational Standard of Higher Education providing training in 49.03.01 Physical culture (bachelor's degree), registered in the Ministry of Justice of Russia on 25.08.2014 N 33796. (URL address is http://fgosvo.ru/fgosvo/92/91/ 4/99). Access mode: 17.08 .2018

Fedorov, V.V., Blinov, L.V. (2017). Integration of professional competencies of a sport coach in higher physical education // Theory and practice of physical culture. No. 7., pp. 14-16.

Forster, J. (2010). Students as Top-athletes "Promotion of the DualCareer in sports and academics". Report presented at the EAS conference in Berlin? Germany.

Galimov, A.M. (2016). Organizational and pedagogical conditions for integration of the 
educational process with sport activities // Modern problems of science and education. No. 5. pp. 286.

Galimov, A.M., Shchennikova, M.Iu. (2017). Requirements of professional standards as the basis for professional development of students. Education and self-development.Vol. 12. - No. 2 - pp. 73-83.

Gustin, W. (2017). Balancing Sports and Academics / HealthGuidance for better health No 8. Electronic resource http://www.healthguidance.org/entry/15885/1/BalancingSports-and-Academics.html. (Access mode 19.04.2018).

Kotliarova, O.V. (2015). Model of organization of tourist education for student-athletes using information technologies (on the example of "Civic studies" and "Geography" courses). Pedagogical-psychological and medicalbiological problems of physical culture and sports. Vol. 10., No. 1. pp. 61-72.

Latypov, I.K. (2013). The problem of integration of research and educational process with sport training of students at the physical education university. Legacy of major sport events as a factor in the socio-cultural and economic development of the region. International conference on science and practice. Editorial Board: F.R. Zotova, N.Kh. Davletova, V.M. Afanasieva, E.M. Kurochkina. pp. 270-272.

Professional "Athlete" standard, registered in the Ministry of Justice of Russia on 22.05.2014 N 32397. (The URL address is http://fgosvo.ru/docs/101/69/2/5).

Access mode: 17.08.2018.

Research for cult committee - qualifications/dual careers in sports. Electronic resource http://www.europarl.europa.eu/ RegData/etudes/STUD/2016/573416/IPOL_ STU\%282016\%29573416_EN.pdf(Access mode - 04.05.2017).

Sports Academy of Oulu / University Sports of Oulu. Electronic resource http:// www.oulunkorkeakoululiikunta.fi/en/sportsacademy. (Access mode - 17.04.2017).

Student Life Elite Athlete Support / The University Adelaide. Electronic resource http://www.adelaide.edu.au/eliteathletes/services. (Access mode - 05.05.2017).

V.D. Balin, V.K. Gaida, V.K. Gorbachevskii, et al. (2000). Workshop on general, experimental and applied psychology: textbook ed. by A.A. Krylov, S.A. Manichev. - SPb: Peter, pp. 560

Zotova, F.R., Gaznanova, V.M. (2018). Sport and academic career of a student-athlete: a coach's view. Science and Sport: Current Trends. Vol. 18., No. 1 (18). pp. 83-89.

The article is prepared in the framework of the Thematic Plan of applied research projects in the field of physical education and sports. It aims at developing a national assignment for research and higher education institutions under the Ministry of Sport of the Russian Federation for 2017-2019 (the Order of the Ministry of Sport of Russia № 1298 dated 16 December).

\section{Corresponding author:}

Almaz Galimov, Volga Region State Academy of Physical Culture, Sport and Tourism 35, Universiade Village, Kazan, 420010, Russia E-mail: almazga@rambler.ru 